\title{
Tapping into Residents' Perceptions to Diffuse Landscape Water Conservation and Protection Practices $^{1}$
}

\author{
Colby Silvert, Laura Warner, Matt Benge, and John Diaz
}

\section{Introduction}

Despite the importance of water to sustain life, the environment, and economic development, people continue to mismanage scarce water resources, leading to major environmental challenges (Hogeboom, 2020). The United States Environmental Protection Agency (EPA) (2013) estimates that nearly $30 \%$ of the 29 billion gallons of water used by the country's households is allocated for outdoor water use, and during the summer heat, a household's outdoor use may be as high as $70 \%$ of total use. Not only does overwatering lawns reduce freshwater supplies, but the improper use of lawn fertilizer also impairs inland and coastal water quality (Hochmuth et al., 2012; Shuman, 2002). These issues highlight the importance of protecting water quantity and quality through Extension programming targeting residential lawns and landscapes.

Getting residents to change their lawn and landscape practices is challenging because they are influenced by their neighborhood, regional climate, and type of household (Cook et al., 2012). Furthermore, social norms and regulations may dissuade residents from adopting conservation behaviors (Kollmuss \& Agyeman, 2002). Social science research and behavioral theories can help Extension professionals better understand their audience and their social context to tailor their programmatic strategies. In this article, we provide real examples of how university researchers used the Diffusion of Innovations (DOI) theory (Rogers, 2003) to analyze Florida residents' perceptions of landscape conservation and fertilizer behaviors and identify barriers and opportunities to encourage widespread adoption. The information and recommendations are intended for Extension professionals and other practitioners to promote behavior change in household landscaping practices.

\section{Conservation innovations diffuse as people adopt and influence others}

DOI seeks to explain why some innovations become popular quickly while others may never become popular or widely adopted. The theory implies that the speed of diffusion of technologies, behaviors, and ideas (all considered innovations) is largely determined by adopters' characteristics, and how adopters perceive the innovation (Rogers, 2003). Within a social system, the audience can be segmented into the following five adopter stages or groups, ordered according to the groups' receptiveness to adopting an innovation (e.g., an environmentally friendly landscape practice): (1) innovators, (2) early adopters, (3) early majority, (4) late majority, and (5) laggards.

1. This publication is AEC744, one of a series of the Department of Agricultural Education and Communication, UF/IFAS Extension. Original publication date January 2022. Visit the EDIS website at https://edis.ifas.ufl.edu for the currently supported version of this publication.

2. Colby Silvert, graduate assistant; Laura Warner, associate professor; Matt Benge, assistant professor; and John Diaz, assistant professor; Department of Agricultural Education and Communication; UF/IFAS Extension, Gainesville, FL 32611.

The Institute of Food and Agricultural Sciences (IFAS) is an Equal Opportunity Institution authorized to provide research, educational information and other services

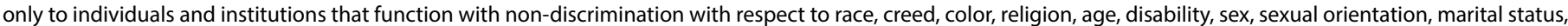

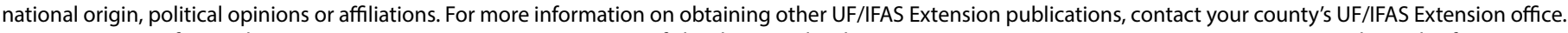
U.S. Department of Agriculture, UF/IFAS Extension Service, University of Florida, IFAS, Florida A \& M University Cooperative Extension Program, and Boards of County Commissioners Cooperating. Andra Johnson, dean for UF/IFAS Extension. 
Table 1. Five Key Perceived Characteristics of an Innovation.

\begin{tabular}{|c|c|c|c|c|}
\hline Relative Advantage & Compatibility & Observability & Complexity & Trialability \\
\hline $\begin{array}{l}\text { Is the conservation } \\
\text { innovation better than } \\
\text { the potential adopter's } \\
\text { previous practice (e.g., } \\
\text { economic, social, and } \\
\text { convenience advantages)? }\end{array}$ & $\begin{array}{l}\text { Is the conservation } \\
\text { innovation compatible } \\
\text { with the potential } \\
\text { adopter's current } \\
\text { behaviors, needs, values, } \\
\text { and beliefs? }\end{array}$ & $\begin{array}{l}\text { How easily can the } \\
\text { potential adopter } \\
\text { observe the results of the } \\
\text { conservation innovation? }\end{array}$ & $\begin{array}{l}\text { How difficult is } \\
\text { understanding and } \\
\text { using the conservation } \\
\text { innovation to the } \\
\text { potential adopter? }\end{array}$ & $\begin{array}{l}\text { Can the potential } \\
\text { adopter test or try the } \\
\text { conservation innovation } \\
\text { before they adopt or } \\
\text { purchase it? }\end{array}$ \\
\hline
\end{tabular}

\section{An innovation's characteristics} influence its chances for adoption

In addition to the adopter stages, DOI proposes that the audience's adoption issignificantly influenced by five characteristics of innovations: relative advantage, compatibility, observability, complexity, and trialability. Extension professionals may reference Table 1 to guide their assessment of an innovation for its perceived level of attractiveness to potential adopters, based on the five characteristics.

\section{Analyzing How Residents Perceive Landscape Conserva-}

tion Practices: The researchers surveyed residents on how they rate landscape water conservation and fertilizer best management practices (BMPs) according to the five perceived characteristics of innovations. Residents were also asked about their adoption of a variety of the conservation and fertilizer BMPs. Examples of the 18 water conservation BMPs included using drip irrigation, drought-tolerant plants, and seasonal adjustment of irrigation. The 11 fertilizer BMPs included following fertilizer label instructions, applying fertilizer based on soil testing, and ensuring landscape contractors are trained in proper fertilizer application. For analysis, the researchers used multiple linear regression to determine which of the five DOI characteristics were statistically significant predictors of Florida residents' adoption of landscape water conservation and fertilizer BMPs. To account for differences between more innovative residents and the rest of the population, the respondents who had adopted the most water conservation practices (top 10\%) and fertilizer practices (top 16\%) were analyzed separately and compared (Warner et al., 2019; Warner et al., 2020). We share key findings from these analyses in the following section.

\section{Key Findings to Accelerate Landscape Conservation}

The studies described below identified the extent of Floridians' engagement in water conservation and fertilizer BMPs. This research examined the most important characteristics of innovations that can be used to help diffuse these landscape BMPs. There were also some key differences in educational needs among people who were more and less engaged in using BMPs.

\section{Engagement in BMPs}

- The level of engagement in water conservation and fertilizer BMPs varied substantially. Some of these practices were highly used by the majority while others were not. These findings highlight the diversity in use of, and perceptions associated with, these BMPs.

- Most Floridians were currently following watering restrictions (this may be due in part to legal requirements to do so) and had low-water-consuming plants (e.g., native grasses and shrubs) in their yard, while less than half were engaged in other conservation practices, such as using rain sensors to turn off irrigation when there was adequate precipitation and replacing high-volume irrigated areas with low-volume irrigation.

- Floridians are most likely to always read and follow fertilizer label directions and clean up any fertilizer spilled on paved surfaces. They are least likely to ask fertilizer applicators about their professional training/certification, or to use soil test results to understand what nutrients are needed.

\section{Characteristics of innovations influencing BMP engagement}

- When considering how the five characteristics of innovations influenced Floridians' overall fertilizer BMP adoption, compatibility, trialability, and relative advantage were significant predictors.

- When considering how the five characteristics of innovations influenced Floridians' overall adoption of water conservation practices, compatibility, trialability, and relative advantage were significant predictors.

- In the studies on both water conservation and fertilizer BMP engagement, compatibility was the most important predictor, followed by trialability and relative advantage.

- Complexity and observability were not significant predictors of either water conservation or fertilizer BMP engagement. 
- These findings provide an important starting point for understanding the drivers of adoption of suites of water conservation and fertilizer BMPs broadly. Specifically, three of the five characteristics appear to be influential on residents' landscape behaviors.

\section{Educational needs relating to level of BMP adoption}

- Compared to those who were using more BMPs, less engaged individuals were not as likely to engage in active learning opportunities such as visiting an Extension office, engaging in a Twitter chat, getting trained as a volunteer, or participating in a webinar.

- There were no differences in educational preferences between more and less innovative individuals on passive learning opportunities such as reading a fact sheet, watching a video, or visiting a website.

- Complexity and observability were significant factors among innovative individuals' fertilizer BMP and water conservation engagement. For instance, perceptions that research-based landscape BMPs are not overly complicated and opportunities to see the results of adopting them are important among those who are first to adopt. This finding may be due to the likelihood that more innovative individuals had actually used or been exposed to the BMPs to grasp their complexity and observability while less innovative individuals had less exposure. Nonetheless, neighborhood and HOA expectations and social norms likely contribute to observability by encouraging or discouraging existing examples for others to see.

\section{How Extension Professionals Can \\ Use the Findings}

Extension professionals and other practitioners can use these findings in a number of ways to integrate DOI into their programs to support diffusion of research-based water conservation and fertilizer BMPs. They should consider the following:

- Identify the current extent of adoption of BMPs within their target audience. BMPs with high adoption rates may need minimal support to be self-sustaining, while others with low adoption rates may need more attention. To understand adoption rates, it may be helpful to read the Warner et al. (2020) EDIS article (https://edis.ifas.ufl. edu/publication/WC345), which presents findings from the 2018 statewide survey on Floridians' engagement in landscape water conservation BMPs. Additionally, research is needed to better understand the current state of BMP adoption.
- Emphasize how BMPs are compatible with a target audience's values, yard care routines, community aesthetics, and budget. Doing this requires having a deep understanding of the audience. For example, an Extension professional promoting the use of low-water plants in a community with very specific aesthetic codes would want to emphasize how specific low-water plants can fit and thrive within the prescribed landscape. An Extension professional tasked with disseminating information about calculating appropriate fertilizer rates among environmentally motivated individuals might emphasize how this practice can protect local wildlife. When people perceive a new practice is compatible with their lives, they will be more likely to adopt.

- Provide opportunities for residents to try out BMPs before deciding whether or not to adopt them. Hands-on activities such as fertilizer-selection simulations or opportunities to adjust irrigation controls can provide these critical opportunities to try out BMPs. When opportunities are provided so people can try out new practices before having to make a decision, they will be more likely to adopt.

- Emphasize how BMPs are better than the practices they replace. Landscape BMPs may provide opportunities to save money, increase turfgrass health, improve landscape aesthetics, or reduce the amount of time spent on yard care, compared to current practices. When characteristics such as these are brought to the forefront of education and BMPs are perceived as being better than other practices previously used, people are more likely to adopt.

- Provide educational materials in a variety of formats that reach more and less innovative individuals. Passive Extension education (i.e., websites, fact sheets) are likely to reach a broader audience and may be used to raise awareness and help people develop initial positive perceptions. More active Extension education (i.e., group trainings, webinars) are likely reaching people who are already aware and somewhat motivated to adopt, and they should bring in more complex material and persuasive elements as individuals further develop their perceptions.

\section{Conclusion}

The importance of fresh water cannot be overstated, because its use varies widely from drinking to landscape. Specifically to Florida, the scarcity of freshwater resources is compounded by the daily influx of new residents and overuse by residents. Extension professionals and practitioners working with water quality, water conservation, and landscape practices need to understand how to better build 
quality outreach programs to engage residents in more efficient use of their available water resources. Extension professionals can apply DOI to better understand why residents choose (or do not choose) to adopt innovations in their landscape, and in turn, make a bigger impact on Florida's environment and water supply. Specifically, compatibility, trialability, and relative advantage tend to be the most important characteristics that can be incorporated into education and outreach to improve uptake of BMPs. These characteristics should be contextualized for the specific innovation being promoted and the audience being targeted. Extension professionals can also use DOI to segment the residential population, according to receptiveness to conservation innovations, to strategically target residents most likely to adopt and then influence others. To learn more about the research referenced throughout this article, the two full studies can be found in the Journal of Agricultural Education and Urban Forestry and Urban Greening.

\section{References}

Cook, E. M., Hall, S. J., \& Larson, K. L. (2012). Residential landscapes as social-ecological systems: A synthesis of multi-scalar interactions between people and their home environment. Urban Ecosystems, 15(1), 19-52. https://doi. org/10.1007/s11252-011-0197-0

Environmental Protection Agency. (2013). Water-smart landscapes. https://www.epa.gov/sites/default/files/2017-01/ documents/ws-outdoor-water-efficient-landscaping.pdf

Hochmuth, G., Nell, T., Unruh, J. B., Trenholm, L., \& Sartain, J. (2012). Potential unintended consequences associated with urban fertilizer bans in Florida-A scientific review. HortTechnology, 22(5), 600-616. https://doi. org/10.21273/HORTTECH.22.5.600

Hogeboom, R. J. (2020). The water footprint concept and water's grand environmental challenges. One Earth, 2(3), 218-222. https://doi.org/10.1016/j.oneear.2020.02.010

Kollmuss, A., \& Agyeman, J. (2002). Mind the gap: Why do people act environmentally and what are the barriers to pro-environmental behavior? Environmental Education Research, 8(3), 239-260. https://doi. org/10.1080/13504620220145401

Rogers, E. M. (2003). Diffusion of innovations. (5th ed.). Simon and Schuster.

Shuman, L. M. (2002). Phosphorus and nitrate nitrogen in runoff following fertilizer application to turfgrass. Journal of Environmental Quality, 31(5), 1710-1715. https://doi. org/10.2134/jeq2002.1710

Warner, L. A., Lamm, A. J., \& Silvert, C. (2020). Diffusion of water-saving irrigation innovations in Florida's urban residential landscapes. Urban Forestry \& Urban Greening, 47, 126540. https://doi.org/10.1016/j.ufug.2019.126540

Warner, L. A. S., Momol, E., Lewis, C., Wichman, T., Wilber, W., \& Reisinger, A. J. (2020). Floridians' engagement in landscape best practices to protect water resources: Information from a 2018 survey. EDIS 2020 (1). https://doi. org/10.32473/edis-wc345-2020

Warner, L. A., Silvert, C., \& Benge, M. (2019). Using adoption and perceived characteristics of fertilizer innovations to identify Extension educational needs of Florida's residential audiences. Journal of Agricultural Education, 60(3), 155-172. https://doi.org/10.5032/jae.2019.03155 